\title{
Prediction and measurement of the heat transfer coefficient in a direct oil-cooled electrical machine with segmented stator
}

\begin{abstract}
This paper presents the prediction and measurement of the heat transfer coefficient (HTC) in a direct oil-cooled electrical machine with segmented stator. The measurements were done using the double-sided thin film heat flux gauges. While these are often used in transient measurements of the HTC on gas turbine components, the technique was adapted so that steady state measurements can be applied for oil-cooled machines. The Yokeless and Segmented Armature axial flux machine was used as a case study for applying this measurement technique. The paper explores the challenges linked with this technique when applied to this environment and develops empirical correlations for estimating the HTC. The experimental results were compared with CFD simulations and existing pipe flow correlations.
\end{abstract}

Index Terms - electric machines, cooling, thermal modeling

\section{NOMENCLATURE}

$\begin{array}{lll}\alpha & \text { Temperature coefficient of resistivity } & {[1 / \mathrm{K}]} \\ \mathrm{D}_{\mathrm{h}} & \text { Hydraulic diameter } & {[\mathrm{m}]} \\ \mathrm{h} & \text { Heat Transfer Coefficient }(\mathrm{HTC}) & {\left[\mathrm{W} / \mathrm{m}^{2} \mathrm{~K}\right]} \\ \mathrm{I} & \text { Current } & {[\mathrm{A}]} \\ \mathrm{k} & \text { Thermal conductivity } & {[\mathrm{W} / \mathrm{mK}]} \\ \mathrm{L} & \text { Pipe length } & {[\mathrm{m}]} \\ \mu & \text { Dynamic viscosity } & {[\mathrm{kg} / \mathrm{mK}]} \\ N u & \text { Nusselt number } & \\ v & \text { Kinematic viscosity } & {\left[\mathrm{m}^{2} / \mathrm{s}\right]} \\ \mathrm{p} & \text { Wetted perimeter } & {[\mathrm{m}]} \\ \mathrm{P} & \text { Electrical Power } & {[\mathrm{W}]} \\ \mathrm{Pr} & \text { Prandtl number } & \\ \mathrm{q} & \text { Heat flux } & {\left[\mathrm{W} / \mathrm{m}^{2}\right]} \\ \mathrm{R} & \text { Electrical Resistance } & {[\mathrm{\Omega}]} \\ \mathrm{Re} & \text { Reynolds number } & \\ T & \text { Temperature } & {[\mathrm{K}]} \\ \mathrm{v}_{f} & \text { Fluid velocity } & {[\mathrm{m} / \mathrm{s}]} \\ \mathrm{V} & \text { Voltage } & {[\mathrm{V}]} \\ \mathrm{x} & \text { thickness } & {[\mathrm{m}]}\end{array}$

\section{INTRODUCTION}

$\mathrm{R}$ ECENT developments in axial flux permanent magnet machines enable higher torque densities and higher efficiencies making them suitable for applications such as road transportation or wind energy generation [1]-[3]. The quest to improve torque density requires that both the electromagnetic and thermal aspects of the machine are optimized. While there are numerous papers demonstrating improvement in electromagnetics, studies demonstrating improvements in the thermo-fluids aspects of electrical machines are fewer [4]. As the winding insulation is rated to a maximum operating temperature the hottest spot in the stator windings limits the machine life and torque ratings. Therefore accurate thermal modelling of the machine allows proper choice of material, avoids unnecessary derating and reduces safety factors thus allowing high torque densities to be achieved. Thermal modelling is performed either through analytical methods such as lumped parameter (LP) models [5-8], or numerical techniques such as finite element analysis [9]-[13] and computational fluid dynamics (CFD) [14]-[17]. A review of the techniques used for electrical machine thermal modeling is provided in [18].

One of the critical parameters that are required for accurate thermal modelling of electrical machines is the heat transfer coefficient (HTC). This is difficult to determine and is obtained from experiments [17], [19], [20], empirical correlations of ideal geometries [21]-[23], or CFD simulations [14]-[17]. Geometrical differences from the ideal geometries of electrical machines may lead to inaccuracies when using HTC correlations for ideal geometries [24]. Moreover, CFD derived values require experimental validation. Despite the higher current density of liquid cooled electrical machines and the importance to produce accurate thermal models, to the authors' knowledge no experimental research that measures the heat transfer coefficient in liquid cooled machines exist. This is the subject of this paper, which fills this gap by applying thin film heat flux gauges to measure the HTC in a direct oil-cooled electrical machine.

The paper is organized in the following manner. Section II sets the boundary conditions to which this research is applied by presenting a description of the Yokeless and Segmented Armature (YASA) electrical machine [1] used as a test case study in the research. Section III presents prediction methods using analytical flow pipe correlations and CFD simulations. Section IV describes the measuring technique, gauge manufacturing and calibration and finally describes the experimental process on a quarter-motor test rig. The post processing techniques to derive the HTC from the experiment are shown in Section V, which also compares the correlations and CFD model to experimental results. Finally, Section VI provides a discussion of the work presented in this paper.

\section{The Yasa Machine: A Test CASE StUdy}

The YASA machine, shown in Fig. 1, is derived from the NS Torus-S topology. By removing the stator yoke, enlarging the pitch of the teeth and wrapping a high fill factor short end winding coils around each of the individual stator poles, the iron in the stator is reduced by around $50 \%$. This increases the 
torque density by around $20 \%$ when compared to other axial flux machines. The peak efficiency can be maintained at over $95 \%$ [1]. This architecture has recently received increasing attention and several variants can be found in the literature [2], [25]-[27]. Each stator pole piece of the YASA machine is made from concentrated windings of square cross section wire. Epoxy is typically injected in the windings to fill the air gaps, which also leaves the surfaces of the pole pieces smooth. In this machine, the stator is enclosed in a glass fiber casing allowing liquid coolant to be injected into the stator in direct contact with the windings. Flow stoppers are used to avoid the flow bypassing around the periphery, dividing the machine into four similar sections as shown in Fig. 2.

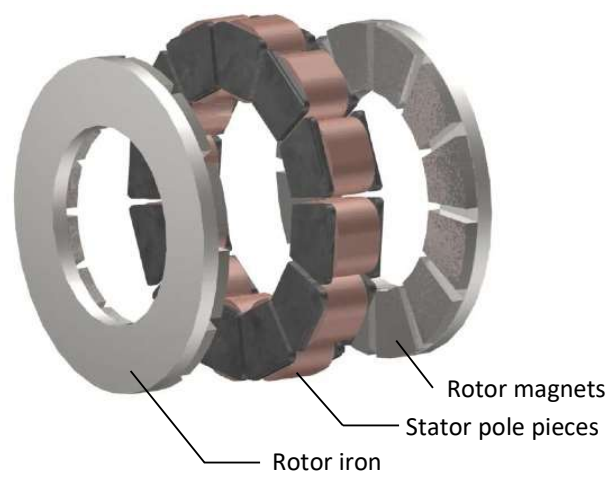

Fig. 1. Schematic of the YASA topology, reproduced from [1]

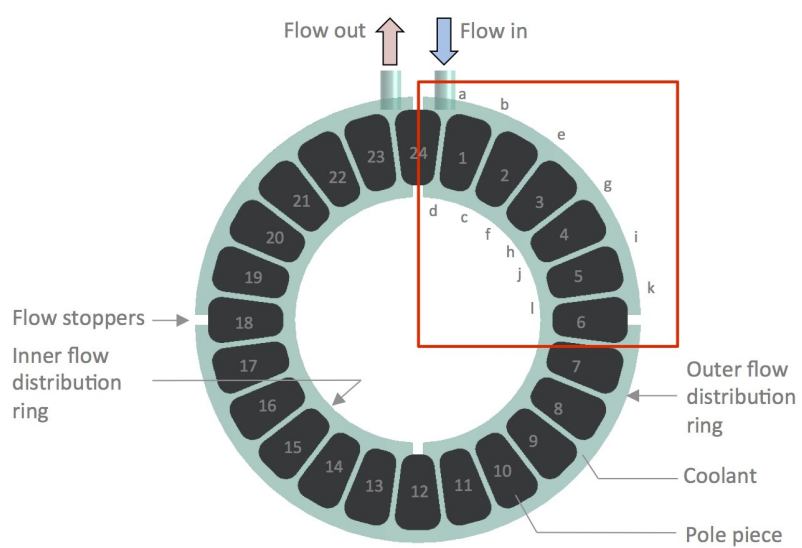

Fig. 2. Schematic of the YASA direct liquid cooled stator. Highlighted Quadrant replicated for testing in Section IV

Throughout this work, the direct drive motor YASA-750 motor and therefore the machine geometry and specifications as shown in [28] are considered.

\section{PREDICTION OF THE HTC}

\section{A. Empirical laminar pipe flow correlations}

The Nusselt number $\mathrm{Nu}$ for laminar flow in short pipes and developing thermal and fluid boundary layer can be determined using the Seider Tate equation [29]:

$$
N u_{S-T}=1.86(\operatorname{Pr} R e)^{0.33}\left(D_{\mathrm{h}}\right)^{0.33}\left(\frac{\mu_{b}}{\mu_{W}}\right)^{1.14}
$$

Conversely, [30] defines the Nussel number for laminar flow of fluids with Prandtl no. $>5$ and developing hydrothermal boundary layer as:

$$
N u_{P r>5}=\left(\frac{\mu_{b}}{\mu_{u v}}\right)^{0.14}\left[3.66+\frac{0.0668 \operatorname{Pr} R e\left(\frac{D_{h}}{L}\right)}{1+0.04\left(\operatorname{Pr} \operatorname{Re}\left(\frac{D_{h}}{L}\right)\right)^{0.667}}\right]
$$

In which Re is the Reynolds number defined as:

$$
\operatorname{Re}=\frac{v_{f} D_{h}}{v}
$$

$D_{\mathrm{h}}$ is the hydraulic diameter defined as

$$
D_{\mathrm{h}}=\frac{4 A}{p}
$$

The ratio of dynamic viscosities $\left(\frac{\mu_{b}}{\underline{k}_{v}}\right)^{0.14}$ is a corrective factor to account for the change in viscosity at the hot wall surface.

\section{B. CFD Modelling}

Following validation cases on channel flows, 2D and 3D CFD models were developed to predict the HTC on the pole piece surfaces. A 2D CAD model of the flow domain highlighted in Fig. 2 was developed. Details of the geometry and set boundary conditions are shown in Fig 3.

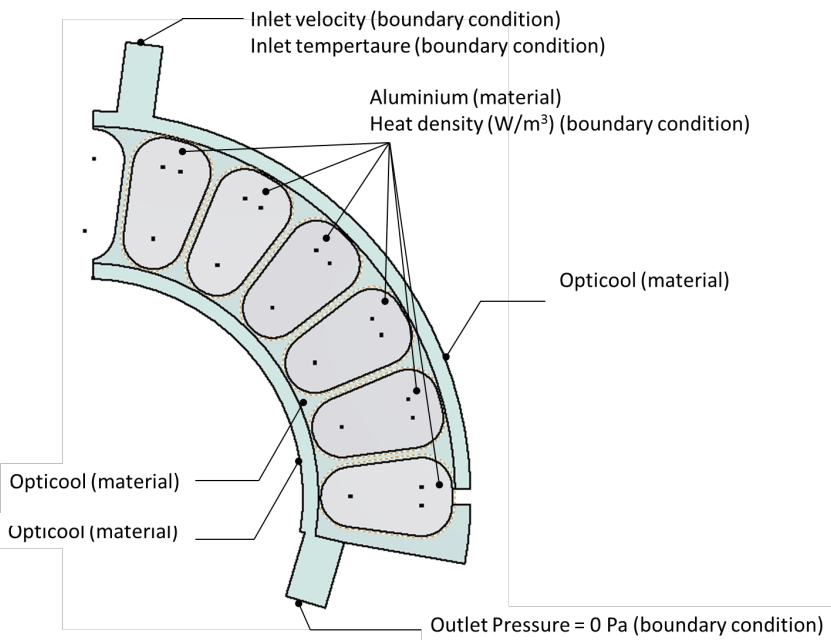

Fig 3. Details of the CAD geometry and boundary conditions applied to the 2D model

The geometry within the stator channels was meshed at a higher density than the flow distribution rings. Triangular elements were set with an enhanced boundary mash made of 15 layers with a factor of 1.05 and a gradation of 1.15 . The final mesh size consisted of $0.37 \mathrm{M}$ elements and is shown in Fig 4. Due to the low Reynolds numbers across all channels, the simulation was run with a Laminar model. The author experimented with fixed and temperature dependent coolant properties, conjugate and segregated simulations and different advection schemes, which govern transport quantities such as velocities and temperature through the flow domain. 


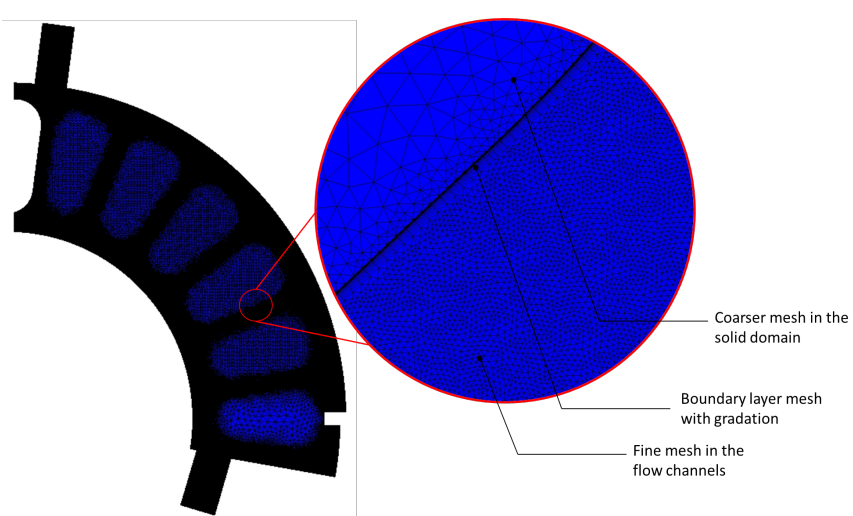

Fig. 4. Mesh setup for the 2D model with insert of the uniform mesh in the fluid channels and details of the boundary layer mesh.

Advection schemes are described in [31]. The properties of the coolant are defined in Table I.

TABLE I

VARIATION OF COOLANT PROPERTIES WITH TEMPERATURE T $\left[{ }^{\circ} \mathrm{C}\right]$

\begin{tabular}{lll}
\hline \hline Density, $\rho\left[\mathrm{kg} / \mathrm{m}^{3}\right]$ & $p=-0.0052 T^{2}+0.2667 T+786.76$ & $(5)$ \\
Dyn. visc. $\mu[\mathrm{Pa} . \mathrm{s}]$ & $\mu=0.0079 e^{-0.025}$ & $(6)$ \\
Heat Capacity, $c$ & $c=-0.028 T^{2}+5.9105 T+2044.9$ \\
{$[\mathrm{~J} / \mathrm{kgK}]$} & \\
Thermal conductivity, $k$ & $k=1 e^{-7} T^{2}-8 e^{-5} T+0.1376$ \\
{$[\mathrm{~W} / \mathrm{mK}]$}
\end{tabular}

A 3D CFD model of a quarter of the motor was also developed but found to require a mesh in the order of $>10 \mathrm{M}$ elements. This proved to be very computationally intensive and time consuming. Hence the flow domain for the 3D model was reduced to a single channel between the pole pieces as shown in Fig 5, which also shows the boundary conditions set to the 3D CFD model.

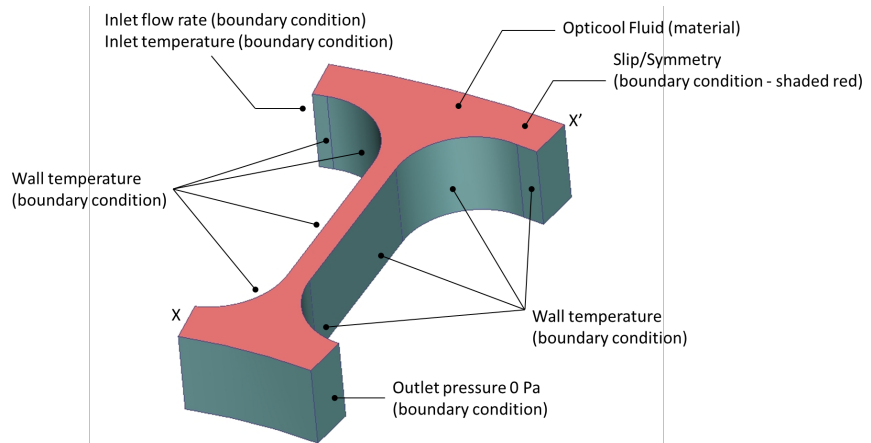

Fig 5. Details of the boundary conditions applied to the single channel 3D model

The 3D mesh was formed from tetrahedral elements with a minimum refinement length set to 0.5 and the maximum size set to 1.8 at the surfaces. The boundary layer mesh was made of 15 layers with a factor of 0.75 and gradation of 1.15 . A grid sensitivity analysis was performed with the final mesh resulting in a total of $4.3 \mathrm{M}$ elements, and is shown in Fig. 6

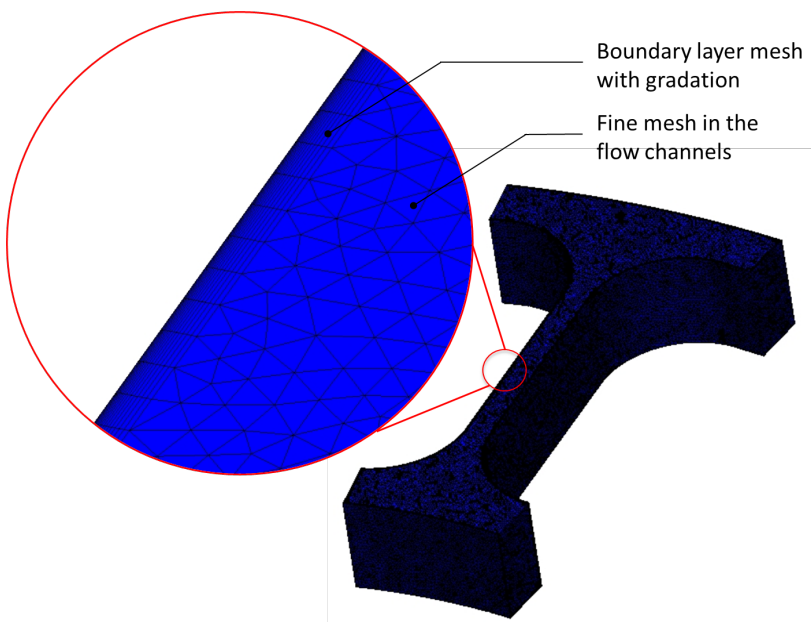

Fig. 6. Highlighted portion of the liquid channel simulated in CFD

Both 2D and 3D models were found to be most accurate with a conjugate, laminar model using ADV 4 and temperature dependent coolant properties. The simulation was repeated with tighter mesh settings until the temperature variation of the pole piece was $<2 \%$. A solution of the $2 \mathrm{D}$ model is found in approximately 3 hours while the $3 \mathrm{D}$ model is solved in approximately 12 hours. The simulations were run for a number of inlet flow rates, oil inlet temperature and pole piece surface temperature to achieve a plot of HTC with Re.

\section{EXPERIMENTAL WORK}

A. Thin Film gauges: application to oil-cooling The convective heat transfer coefficient $\mathrm{h}$ is defined as:

$$
h=\frac{\dot{q}}{\left(T_{s}-T_{r e f}\right)}
$$

The fluid reference temperature $T_{\text {ref }}$ should theoretically be the local fluid temperature above the surface. However, this is difficult to measure and is often replaced by an alternative fluid temperature which is characteristic of the heat transfer driving temperature, for example the inlet temperature [17, 32]. This is hence applied for defining CFD and experimental HTC values. Thin film heat flux gauges are a type of film resistance measuring device that are used to establish the heat flux perpendicular to the surface of the object measured. The change in electrical resistance of a platinum sensor that is sputtered onto an insulating substrate is measured. The electrical resistance of the gauges, $\mathrm{R}$, is dependent on temperature and can be described by the linear relationship:

$$
R=R_{o}+a \cdot\left(T-T_{o}\right)
$$

The surface temperature is therefore inferred by the change in electrical resistance and the gauge parameters, which are derived following an initial calibration process.

The high frequency response $(100 \mathrm{kHz})$ of the thin film gauges has made them suitable for transient techniques in gas turbine applications, [33]. Test times are typically $10 \mu \mathrm{s}$ to $1 \mathrm{~s}$, 
during which a pulse of hot air is passed over the test piece and the change in voltage across the gauge, whilst supplied with a constant current, is recorded. The time history of voltage is then used to determine the change is gauge resistance, and hence temperature, with respect to time. The calculation of heat flux from the temperature history can be performed in a number of methods, for example the impulse response method documented by [34]. Finally, the convective heat transfer coefficient (HTC) and adiabatic wall temperature (allowing for compressibility effects) is determined from a linear regression of heat flux and driving temperature.

In this research, the double-layered thin film gauge shown in Fig. 7 is used to determine the HTC. In the context of an oil-cooled component, the large thermal capacity of the oil cooling system makes the transient impulse response unsuitable. The technique presented here is modified from the transient method in that the metal substrate is heated until a steady state condition is reached. The metal substrate temperature was measured by two k-type bare-bead thermocouples located on the upper and lower walls of the pole piece. These measurements agreed to within $0.5 \mathrm{~K}$ showing the block was isothermal during testing.

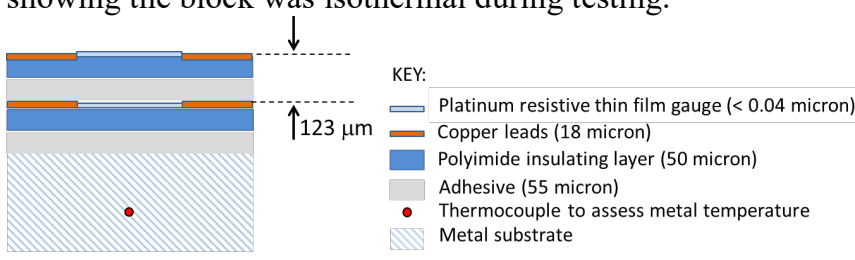

Fig. 7. Schematic of a double-sided thin film heat flux gauge.

Steady state heat flux was determined using the onedimensional Fourier conduction equation across the insulating substrate:

$$
\dot{q}=(k / x)\left(I_{s u b s_{-} b}-I_{s u b s_{-} t}\right)
$$

In which the temperatures $T_{s u b s_{-} t}$ and $T_{s u b s_{-} b}$ are derived from the measured resistances of the thin film gauges on top and below the insulation substrate. To determine the heat flux and hence the heat transfer coefficient, the thermal properties of the heat flux gauges are also required. The thermal properties of the polyimide and glue layers used are well documented by the manufacturers and have very similar properties, and such can be regarded as one material. The thermal properties of the substrate between the heat flux gauges are shown in Table II.

TABLE II

SUBSTRATE MATERIAL PROPERTIES

\begin{tabular}{cc}
\hline \hline Thermal conductivity $\mathrm{k}[\mathrm{W} / \mathrm{mK}]$ & 0.46 \\
Substrate thickness x [m] & $1.05 \mathrm{e}-6$ \\
Product $\mathrm{k} / \mathrm{x}\left[\mathrm{W} / \mathrm{m}^{2} \mathrm{k}\right]$ & 4380 \\
\hline
\end{tabular}

B. Manufacturing and Calibration of Thin Film gauges

The gauges were manufactured at the Southwell Thermofluids Laboratory at the University of Oxford. Details of the fabrication process of thin film gauges are found in [35]. A pole piece replica was manufactured in aluminium and instrumented with eight double-layered thin film gauges on each side of the oil flow channel, as shown in Fig. 8
Aluminium was chosen due to its high conductivity, which aids uniform heating of the segmented pole pieces, and ease of manufacturing.

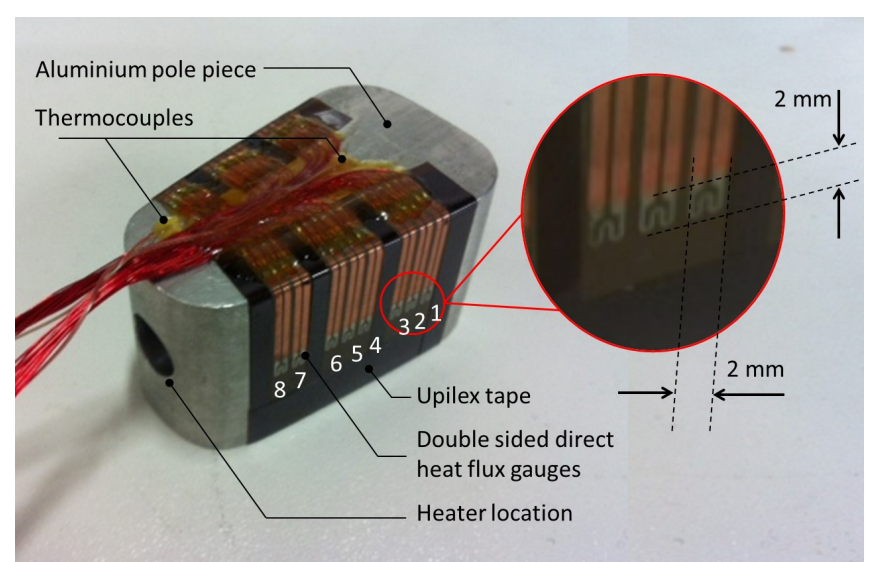

Fig. 8. Aluminium test piece with mounted direct heat flux gauges.

As the gauge parameters are affected by the manufacturing and mounting process, calibration is performed after the thin film gauges are mounted on the test piece. It was shown in equation (2) that calculating the gauge temperature requires the values of $R_{o}$ and $\alpha$. These values are found by calibrating the gauges at isothermal conditions for a range of working temperatures. A reference temperature sensor that gives a calibrated temperature measurement is used, thus:

$$
R_{\text {calib }}=R_{o}+\alpha \cdot T_{\text {calib }}
$$

The calibration process was also performed at the Southwell Thermo-Fluids Laboratory using a bespoke calibration facility. The facility uses a measurement system based on National Instruments PXI systems with a thermostatically controlled water bath. The water bath temperature is interfaced through a serial interface and a relay switch module is controlled by a Labview script and allows to measure up to 96 resistances simultaneously. During the calibration process, the instrumented test piece was sealed in a plastic bag and placed in a water bath. The water bath temperature was increased from $20{ }^{\circ} \mathrm{C}$ to $45{ }^{\circ} \mathrm{C}$ in steps of $5{ }^{\circ} \mathrm{C}$. The pole piece temperature and water bath temperature were monitored to ensure isothermal conditions. These temperatures and resistances of the thin film gauges were recorded. The linear relationship of each gauge resistance was plotted against the known set of temperatures. This allows the extraction of the temperature coefficient $\alpha$ and reference resistance $R_{o}$ for each gauge. An example of a typical calibration chart for one thin film heat flux gauge is shown in Fig. 9.

While for platinum $\boldsymbol{a}$ is found to experience very little variation with temperature and is considered constant, $R_{o}$ sometimes experiences a drift [35]. This is mainly in high temperature environments synonymous with aerospace components, and is likely due to induced stresses and relaxation of the gauge connections. However, although the measurements presented in this research are low temperature $\left(<100{ }^{\circ} \mathrm{C}\right)$, steady state experiments take longer to settle. 


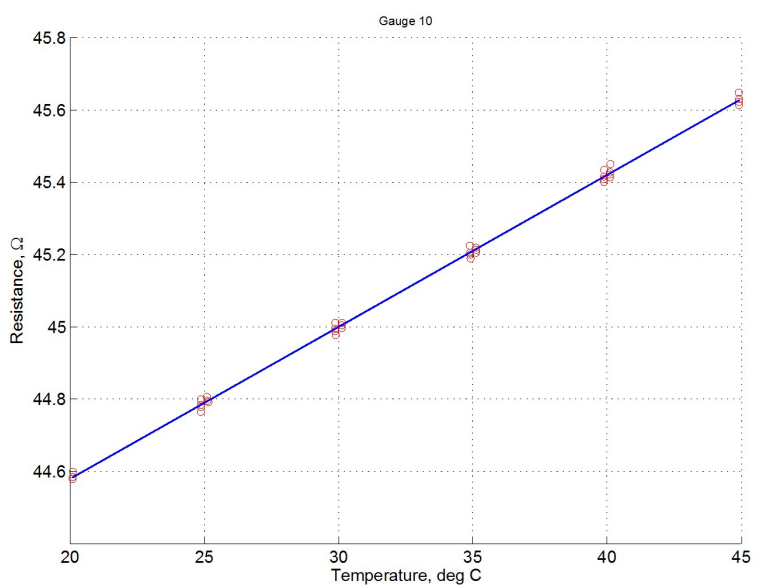

Fig. 9. Example of a calibration chart for a thin film gauge, from which the values of temperature coefficient $\alpha$ and reference resistance $R_{0}$ (y-intersect at $\mathrm{T}=0{ }^{\circ} \mathrm{C}$ ) for each gauge is determined.

The complete set of tests presented here, were performed over a few days. Therefore to counter for any possible drift in $R_{o}$ during the course of the testing period, an isothermal test was performed at the start of each measured data set. Hence, during the experiment, temperature of the each gauge was determined as a function of the calibration parameter $\alpha$ and measured parameters $R, R_{\text {iso }}$ and $T_{\text {iso }}$ :

$$
T=\left(\frac{R-R_{\text {iso }}}{\alpha}\right)+T_{\text {iso }}
$$

\section{Assessment of the heating system}

The steady state experiment required the aluminium test piece to be heated. To assess this, the heating system was simulated in Autodesk CFD Simulation. A three-dimensional model of the aluminium block with heater was designed and meshed. The cartridge heater was set to be stainless steel and was set to produce a heat generation of $80 \mathrm{~W}$. A thermal contact resistance of $0.3 \mathrm{~K} / \mathrm{W}$ was applied between the heater and the aluminium block to represent the thermal grease. The presence of the polyamide layer on the heat flux gauges was simulated through an additional resistance at the solid-fluid boundary. An estimated convective heat transfer coefficient of 200 $\mathrm{W} / \mathrm{m}^{2} \mathrm{~K}$ was prescribed on the solid-fluid surface. The external temperature of the aluminium block is presented in Fig. 10.
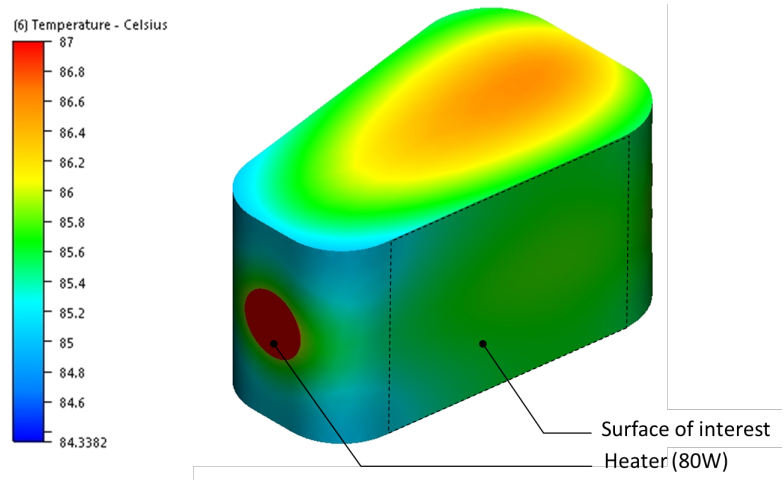

Fig. 10. Simulation of the segmented pole piece to assess the heating system of the pole piece.
It can be seen that a surface temperature of $85^{\circ} \mathrm{C}$ is reached with a variation of less then $1{ }^{\circ} \mathrm{C}$ on the instrumented surface. The model sensitivity to the thermal resistance presented by the polyamide layer was also checked in the simulation. The temperature distribution remains unchanged and therefore this heating method was deemed suitable.

\section{Experimental Setup}

A representative experiment of a quadrant of the stator highlighted in Fig. 2 was set up. Six pole piece replicas were machined in aluminium and used to replace the segmented stator pole pieces. This setup satisfies the scope of this work: to produce a means for measuring the HTC on the surface of an oil cooled pole piece.

Each pole piece was fitted with a $230 \mathrm{~V}, 150 \mathrm{~W}$ cartridge heater of dimensions $10 \mathrm{~mm}$ diameter x $50 \mathrm{~mm}$ length. The heater simulates the total internal heat generation in each pole piece. Silicone based thermal interface material was applied to improve the heat transfer between the heater and the pole pieces. Each pole piece was fitted with two additional thermocouples in $1 \mathrm{~mm}$ holes to monitor the temperature variation in the metal body. The pole pieces were carefully assembled on a plastic base in a test box, recreating the flow channels between them as shown in Fig. 11. The plastic base acts as a thermal insulator and limits the heat transfer to the test box.

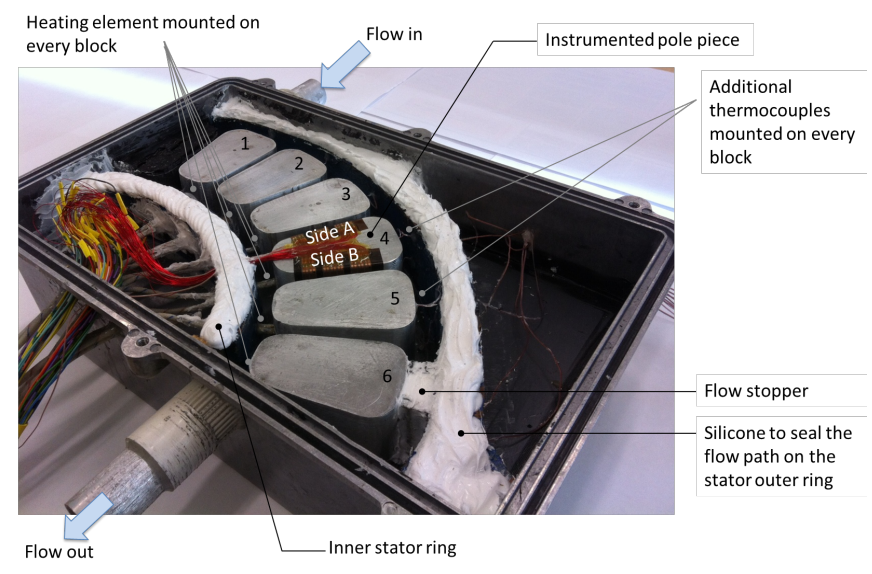

Fig. 11. Test piece representing the first quarter of the motor, mounted with instrumented pole piece

The pole piece heaters were connected to a variable transformer, which was used to regulate the heat input to the pole piece, thus varying the surface temperature of the pole pieces. Current meters and a differential voltage probe were used to measure the current and voltage supplied to the heaters using a PicoScope 3000 series oscilloscope recording at $1 \mathrm{~Hz}$. The heat input $\mathrm{P}$ was calculated as:

$$
\mathrm{P}=\mathrm{I} \cdot \mathrm{V}
$$

The coolant was re-circulated from a reservoir into the test rig and then pumped through a heat exchanger, expelling heat to ambient. The reservoir was also fitted with a heating element to control the inlet temperature of the fluid into the test section. The power input to the coolant heater was also 
regulated through a transformer. The flow rate was regulated using a globe valve and measured using a variable area flow meter, as shown in Fig. 12. A test matrix shown in Table III was performed for flow rates between $1 \mathrm{lpm}$ and $6 \mathrm{lpm}$. Oil inlet temperatures were varied between $25{ }^{\circ} \mathrm{C}$ and $45^{\circ} \mathrm{C}$ and pole piece surface temperature between $30{ }^{\circ} \mathrm{C}$ to $80{ }^{\circ} \mathrm{C}$, in steps of $10{ }^{\circ} \mathrm{C}$. Each experiment was run for 1-3 hours, until steady state conditions were achieved. The steady state values across the final hour were then averaged to determine the oil inlet temperature and the pole piece body temperatures. The gauge resistances were measured from which the temperature difference across the Upilex substrate were determined.

TABLE III

TEST MATRIX FOR OIL FLOW RATES BETWEEN 1 AND 6 LPM

\begin{tabular}{ccccccc}
\hline \hline $\begin{array}{c}\text { Oil inlet } \\
\text { temperature }\left[{ }^{\circ} \mathrm{C}\right]\end{array}$ & \multicolumn{6}{c}{ Pole piece temperature $\left[{ }^{\circ} \mathrm{C}\right]$} \\
\hline 25 & 30 & 40 & 50 & 60 & 70 & 80 \\
35 & & 40 & 50 & 60 & 70 & 80 \\
45 & & & 50 & 60 & 70 & 80 \\
\hline
\end{tabular}

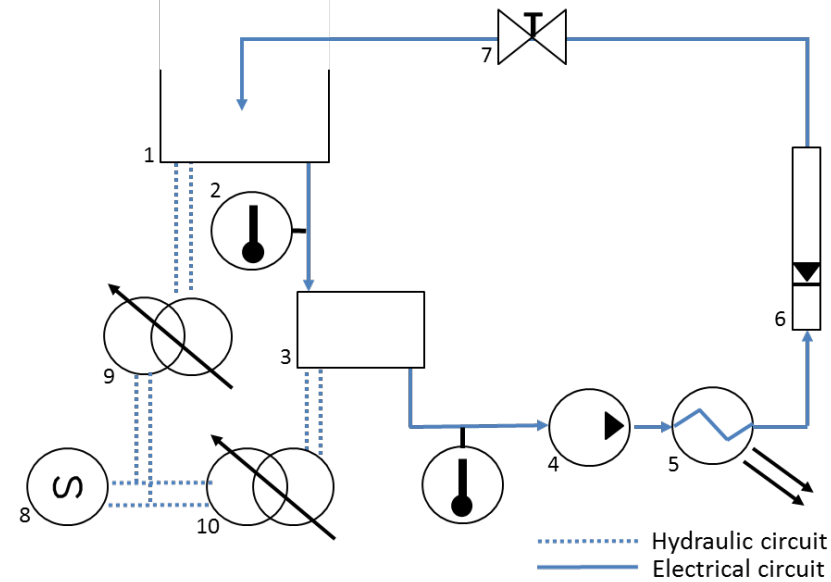

Fig. 12. Test setup with 1) oil reservoir, 2) temperature sensors, 3) test box, 4) pump, 5) heat exchanger, 6) variable area flow meter, 7) globe valve, 8) ac power supply, 9) variable transformer powering fluid heater, 10) variable transformer powering pole piece heaters.

\section{TEST RESUlts}

\section{A. CFD Post Processing Results}

3D CFD models provide insight into the distribution of the heat flux along the entire pole piece surface. An example is shown in Fig. 13

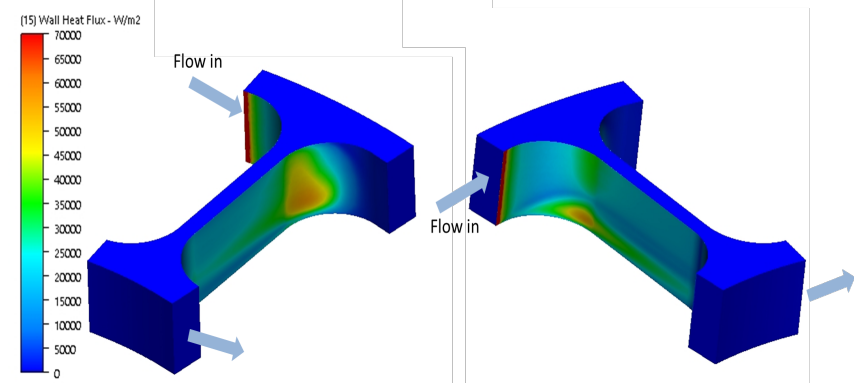

Fig. 13. Heat flux distribution on the pole piece surface at $\mathrm{Re}=150$; (Left) Side 1, (Right) Side 2

\section{B. Post Processing of Experimental Gauge Data}

For each flow rate and oil inlet temperature, the gauge resistances vs. pole piece block temperature was plotted, thus ensuring that the thin film gauges behaved as expected with their resistance increasing with temperature. An example for one gauge and one test is shown in Fig 14

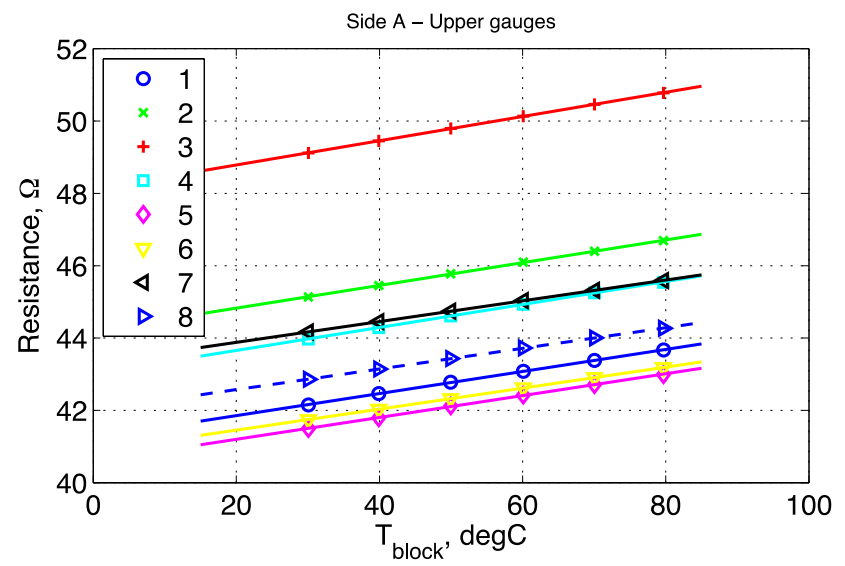

Fig. 14. Variation of gauge resistances with pole piece block temperature

The analysis was repeated for upper and lower gauges on sides $\mathrm{A}$ and $\mathrm{B}$, for multiple flowrates and inlet temperatures. By plotting the linear relationship of the temperature difference across the insulation substrate against the block temperature, the consistency of the gauges was checked. It was generally noted that at a low temperature difference between the oil and the block temperature the gauge readings do not follow the linear trend. An example of this is shown in Fig. 15.
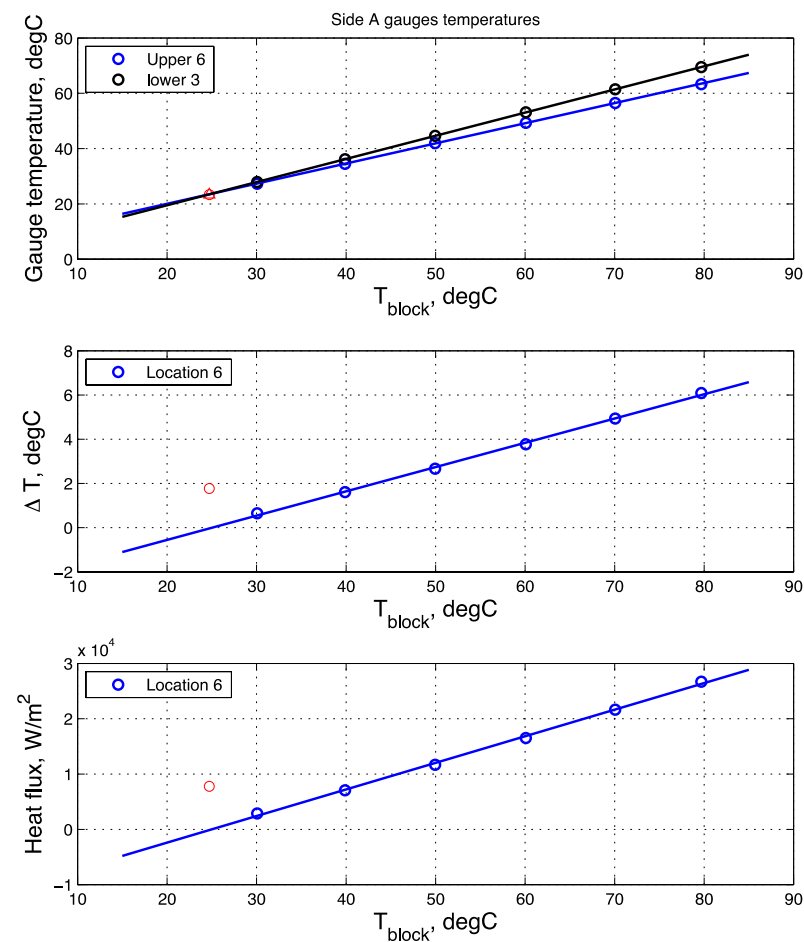

Fig. 15. (Top) Variation of the gauge temperature with pole piece temperature, (Middle) Linear variation of the temperature difference across the insulation substrate with block temperature. The offset temperature in red is ignored during the processing of the gauges. (Bottom) Linear variation of the heat flux across the gauges with block temperature. 
These points were discarded in the calculation of the heat transfer coefficient as they may result in a high uncertainty. A MATLAB script was developed in which eqns. (3)-(5) are solved to determine the local heat flux and local HTC values. An example of the local HTC values is shown in Fig. 16. The reference to side A and side B is indicated in Fig. 11.
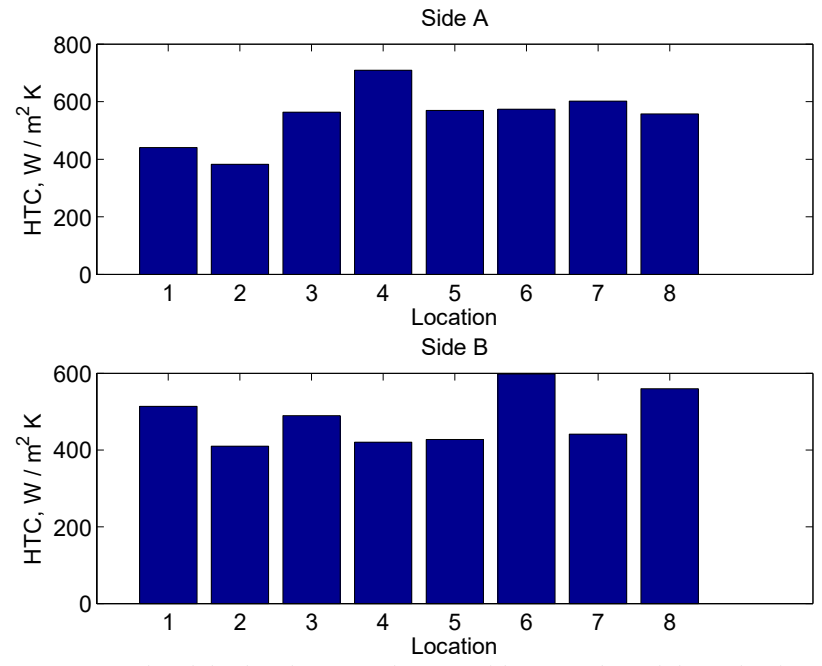

Fig. 16. Example of the local HTC values on sides A and B of the pole piece. Locations 1-8 are referenced to Fig. 8. Sides A and B referenced to Fig. 11.

\section{Comparison of prediction to measured values}

While the experiment provides a map of the local heat transfer coefficient along the pole piece sides for various oil inlet flow rates and temperatures, an average value for each side of the pole piece was calculated. To establish a correlation with the properties of the flow in the channels adjacent to the instrumented sides, the flow distribution within the stator quarter was established using a flow network model described in [36]. The Reynolds number for each flow channel adjacent to sides A and B was therefore calculated and correlated to the measured HTC for each respective side as shown in Fig 17. The non-dimensional Nusselt number $N u$, was defined as:

$$
N u-\frac{h D_{h}}{k}
$$

This was calculated to compare the measurements with existing correlations. A plot of $N u$ vs $R e$ is also superimposed in Fig. 17. The Nusselt number $\mathrm{Nu}$ was linearly correlated with Reynolds number as:

$$
N u=a \cdot R e+b
$$

and applies for the range $20<\operatorname{Re}<180$. Values for $\mathrm{a}$ and $\mathrm{b}$ for each surface are listed in Table IV.

TABLE IV

COEFFICIENTS FOR CORRELATING NU WITH RE

\begin{tabular}{ccc}
\hline \hline Pole Piece Side & Coefficient a & Coefficient b \\
\hline A & 0.015 & 28.89 \\
B & 0.033 & 23.37 \\
\hline
\end{tabular}

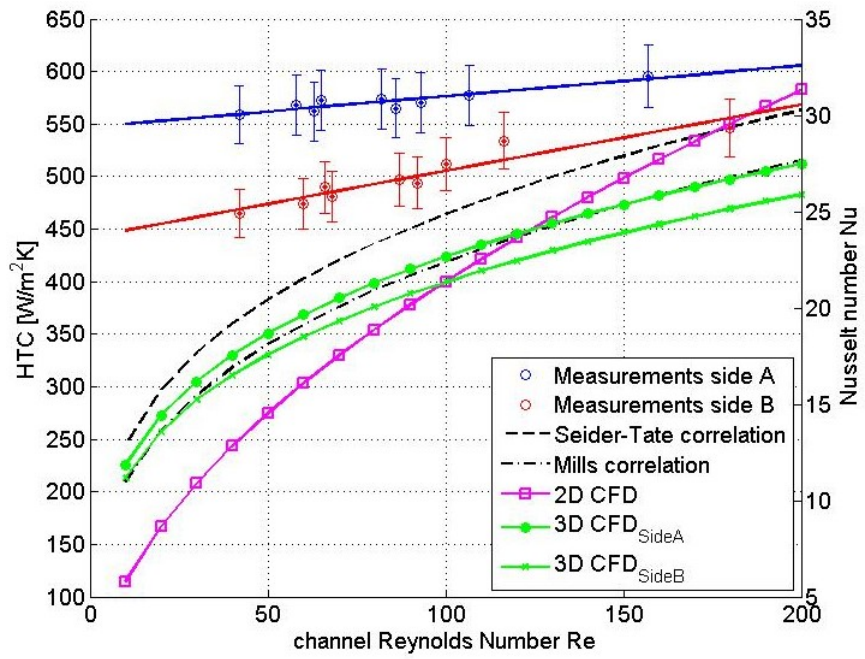

Fig. 17. Example of the mean HTC (on left y-axis) for the two sides of the pole piece with channel Reynolds number. Comparison of the measured nondimensional Nusselt number (on right y-axis) to existing correlations and CFD simulations. Sides A and B are referenced to Fig. 11.

\section{DISCUSSION AND CONCLUSION}

The HTC is often an unknown but required parameter for accurate thermal modelling of electrical machines. To the authors' knowledge no HTC measurements of direct oil cooled electrical machines have been reported in the literature. Hence this paper addresses this gap by presenting a method for measuring the HTC in a directly oil cooled electrical machines with segmented stator by using double layered heat flux gauges. The measrement were correlated with the Reynolds number along the adjacent flow channel and compared with empirical correlations and CFD predictions. Prediction methods were found to underpredict the HTC by $10-30 \%$. However the authors are aware of minor differences between the experiment and simulations which may have in part contributed to this discrepancy, namely: despite the gauge thickness is only $246 \mu \mathrm{m}$, this was not taken into consideration in CFD models and hence the channel flow area is $6 \%$ bigger. Heating cables were not taken into consideration. These may have been a cause to promote turbulence. Likewise, minimal steps in pole surfaces due to the thickness of the Kapton layers may have led to an enhancement in HTC. Both measurements and CFD simulations show that the HTC on each side of the pole piece do not coincide on a single correlation. It is therefore likely that side A experience an added enhancement in the HTC due to the impinging oil on that surface. Non dimensional correlations for each side of the pole piece were hence presented.

\section{REFERENCES}

[1] T.J. Woolmer and M.D. McCulloch, Analysis of the yokeless and segmented armature machine, IEEE International Electric Machines \& Drives Conference, IEMDC'07, 3-5 May 2007, Antalya, Turkey, pp. 704-708.

[2] S.T. Vun, M.D. McCulloch and C.Y. Leong, The development of an electromagnetic analytical design tool for megawatt-scale YASA generators, The 2011 IET Renewable Power Generation Conference, 2011, Edinburgh, UK

[3] M. Lamperth, A. Beaudet and M. Jaensch, Disc motors for automotive applications, in Hybrid and Eco-Friendly Vehicle Conference. IET HEVC2008, 2008, Coventry, UK, pp. 1-5. 
[4] A. Boglietti, Guest Editorial, IEEE Trans. Ind. Electron., Vol. 55, pp. 3498-3499, 2008.

[5] Mellor, P.H., Roberts, D., Turner, D.R., Lumped parameter thermal model for electrical machines of TEFC design, IEE Proceedings-B, Vol. 138, No. 5, Sept. 1991, pp. 205-218.

[6] T.A. Jankowski, F.C. Prenger, D.D. Hill, S.R. O’Bryan, K.K. Sheth, E.B. Brookband, D.F.A. Hunt, Y.A. Orrego, Development and Validation of a Thermal Model for Electric Induction Motors, IEEE Trans. Ind. Electron. Vol. 57, No. 12, pp. 4043 - 4054, Dec. 2010.

[7] J. Nerg, M. Rilla, J. Pyrhonen, Thermal Analysis of Radial Flux Electrical Machines with a High Power Density, IEEE Trans. Ind. Electron. Vol. 55, No. 10, pp. 3543 - 3554, Oct. 2008.

[8] Boglietti, A., Cavagnino, A., Staton, D., Shanel, M., Mueller, M., Mejuto, C., Evolution and Modern Approaches of Thermal Analysis of Electrical Machines, IEEE. Trans. on Ind. Electron., Vol. 56, No. 3, Mar. 2009, pp. 871 882.

[9] A. Tessarolo, C. Bruzzese, Computationally Efficient Thermal Analysis of a Low-Speed High-Trust Linear Electric Actuator with a Three-Dimensional Thermal Network Approach, IEEE Trans. Ind. Electron., Vol. 62, No. 3, pp. 1410-1420, Mar. 2015.

[10] F. Marignetti, V.D. Colli, and Y. Coia, Design of axial flux PM synchronous machines through 3-D coupled electromagnetic thermal and fluiddynamical finite-element analysis, IEEE Trans. Ind. Electron., Vol. 55, no. 10, pp. 3591-3601, Oct. 2008.

[11] T.D. Kefalas, A.G. Kladas, Thermal Investigation of Permanent-Magnet Synchronous Motor for Aerospace Applications, IEEE Trans. Ind. Electron., Vol. 61, No. 8, pp. 4404 - 4411, Aug. 2014.

[12] X. Sun, M, Cheng, Thermal Analysis and Cooling System Design of Dual Mechanical Port Machine for Wind Power Application, IEEE Trans. Ind. Electron. Vol. 60, No. 5, pp. 1724-1733, May 2013

[13] R. Wrobel and P.H. Mellor, Thermal design of high energy density wound components, IEEE Trans. Ind. Electron. Vol. 58, No. 9, pp. 40964104, Sept. 2011.

[14] U. SanAndres, G. Almandoz, J. Poza, G. Ugalde, Design of Cooling Systems Using Computational Fluid Dynamics and Analytical Thermal Models, IEEE Trans. Ind. Electron., Vol. 61, No. 8, pp. 4383-4391, Aug. 2014 [15] C. Jungreuthmayer, T. Bauml, O. Winter, M. Ganchev, H. Kapeller, A. Haumer, C. Kral, A Detailed Heat and Fluid Flow Analysis of an Internal Permanent Magnet Synchronous Machine by Means of Computational Fluid Dynamics, IEEE Trans. Ind. Appl., Vol. 59, No. 12, pp. 4568-4578. Dec. 2012.

[16] C. Micallef, S. J. Pickering, K. A. Simmons and K. J. Bradley, Improved cooling in the end region of a strip-wound totally enclosed fan-cooled induction electric machine, IEEE Trans. Ind. Electron., Vol. 55, No. 10, pp. 3517-3524, Oct. 2008.

[17] D.A. Howey, A.S. Holmes, K.R. Pullen, Measurement and CFD Prediction of Heat Transfer in Air-Cooled Disc-Type Electrical Machines, IEEE Trans. Ind. Appl., Vol. 47, No. 4, pp. 1716-1723, Jul/Aug. 2011. [18] A. Boglietti, A. Cavagnino, D. Staton, M. Shanel, M. Mueller, C. Mejuto, Evolution and Modern Approaches of Thermal Analysis of Electrical Machines, IEEE Trans. Ind. Electron., Vol. 56, No. 3, pp. 871-882, Mar. 2009.

[19] M. Hettegger, B. Streibl, O. Biro, H. Neudorfer, Measurements and Simulations of the Convective Heat Transfer Coefficients on the End Windings of an Electrical Machine, IEEE Trans. Ind. Electron., Vol. 59, No. 5, pp. 2299 - 2308, May 2012.

[20] D.A. Howey, A.S. Holmes, K.R. Pullen, Measurement of stator heat transfer in air-cooled axial flux permanent magnet machines, $35^{\text {th }}$ Annual Conf. of IEEE Trans. Ind. Electron., IECON'09, 3-5 November, 2009, Porto, Portugal, 2009, pp. 1197-1202.

[21] D.A. Howey, P. R. N. Childs, A.S. Holmes, Air-gap convection in rotating electrical machines, IEEE Trans. Ind. Electron., Vol. 59, No. 3, pp. 1367-1375, Mar. 2012

[22] D.A. Staton, A. Cavagnino, Convection Heat Transfer and Flow Calculations Suitable for Electric Machine Thermal Models, IEEE Trans. Ind. Electron., Vol. 55, No. 10, pp. 3509-3516, Oct, 2008.

[23] Camilleri, R., Howey, D.A., McCulloch, M.D., Thermal limitations in air-cooled axial flux in-wheel motors for urban mobility vehicles; A preliminary analysis, Electrical Systems for Aircraft, Railway and Ship Propulsion, ESARS 2012, 16-18 Oct. 2012, Bologna, Italy, pp. 1-8. [24] Romanazzi, P., Howey, D.A., Air-gap comvection in a switched reluctance Machine, $10^{\text {th }}$ Int. Conf. on Ecological Vehicles, and Renewable Energies, (EVER), Mar. 31-Apr, 2, 2015, Monte Carlo, pp. 1-7.

[25] H. Vansompel, P. Sergeant, L. Dupre, A. Van den Bossche, 'A Combined Wye-Delta Connection to Increase the Performance of Axial-Flux PM
Machines With Concentrated Windings', IEEE Trans. Energy Conv., Vol. 27, No. 2, pp. 403-410, Jun. 2012.

[26] B. Zhang, M. Doppelbauer, Numerical iron loss calculation of a new axial flux machine with segmented armature torus topology, $7^{\text {th }}$ IET Int. Conf. on Power Electronics, Machines and Drives (PEMD 2014), 8-10 April 2014, Manchester, UK.

[27] W. Fei, P. Luk, K. Jinupun, A new axial flux permanent magnet segmented armature torus machine for in-wheel direct drive applications, IEEE Power Electronics Specialists Conference, 2008, PESC2008, 15-19 June 2008, Rhodes, pp. 2197-2202.

[28] YASA Motors. Yasa Motors Products,

http://www.yasamotors.com/technology/products/, accessed on: 9/20, 2010. [29] F. Incropera, D. P. Dewitt, T. L. Bergman and A. S. Lavine, Internal flow: Laminar flow in circular tubes; the entry region, in Introduction to Heat Transfer, 5th ed. New York: Wiley \& Sons Inc., 2007, pp. 482-483.

[30] Mills, A.F., Heat Transfer, $2^{\text {nd }}$ ed., Prentice Hall, New Jersey, 1999 [31] Autodesk CFD Simulation Help,

https://knowledge.autodesk.com/support/cfd, accessed on 11/11/2015 [32] Wrobel, R., Vainel, G., Copeland, C., Duda, T., Staton, D., Mellor, P., Investigation of mechanical loss components and heat transfer in an Axialflux PM machine, IEEE Trans. Ind. Appl., Vol. 41 Iss. 4., pp. 3000-3011, 2015

[33] Jones, T. V., 1995, The thin film heat transfer gauges - a history and new developments, Invited lecture, 4th national UK heat transfer conference, IMechE conference transaction, Manchester, pp. 1-12. [34] Oldfield, M. L. G., Impulse response processing of transient heat transfer gauge signals, ASME J. Turbomach., Vol. 130, Iss. 2, 2008, pp. 210-223. [35] Collins, M., Chana, Kam., Povey, T., New Technique for the fabrication of miniature thin film heat flux gauges, Meas. Sci. Technol., Vol. 26, 2015, pp. $1-10$

[36] Camilleri, R., Howey, D.A., McCulloch, M.D., Predicting the Temperature and Flow Distribution in a Direct Oil-Cooled Electrical Machine with Segmented Stator, IEEE Trans. Ind. Electron., Vol. 63, Iss., 1., pp. 82-91, 2016 